\title{
Psychological aspects of headache
}

\author{
P. K. BRIDGES \\ M.D., Ph.D., D.P.M. \\ Consultant Psychiatrist, Regional Neurosurgical Centre, Brook General Hospital, London S.E. 18, \\ the Lewisham Group of Hospitals and Bexley Hospital
}

\begin{abstract}
Summary
Headache is one of the most common symptoms encountered in clinical practice. Its conceptual problems are those of pain in general and some of the theories concerning pain, especially those attempting to relate psychological and physical aspects, are considered.

The classifications which have been suggested for headaches associated with emotional causes are described and it is shown that these are of limited clinical value. Some of the psychogenic causes of headache are considered and the associations of the symptom with various psychiatric illnesses are described. Headache is especially likely to be found with depressive illnesses. The treatments for various psychological types of headache are reviewed.
\end{abstract}

PaIN is one of the commonest symptoms encountered in clinical practice and the head is an especially frequent site of pain. Headache is an experience of everyday occurrence, from which almost everybody suffers on some occasion and its significance will vary from the serious to the trivial. The relationship between physical and psychological contributions to the complaint is also variable and while both aspects occur in the closest association, an attempt at separating the relative emphasis between the two, as far as practical, is necessary in order that effective treatment can be formulated. This process is likely to be time-consuming and it may not be easy because complaints of pain are particularly elusive symptoms to consider objectively.

\section{Pain}

The conceptual problems of headache are those of pain in general, which have been reviewed by Szasz (1957), by Stengel (1965) and by Mersky \& Spear (1967). Like some other sensations, such as anxiety, pain is very difficult to define but most people appear to mean much the same thing in their use of the word. So complex is the problem of definition that it was avoided by Lewis (1942) who felt that 'the attempt could serve no purpose' and by Szasz (1968) who did not believe that a+1 painful states contained an essence-'pain'-that is definable, so he deliberately employed a subjectige approach. Mersky \& Spear (1967), however, fe⿻日乚t that a word so universally valid must be capab隹 of operational definition, for which they suggested 'an unpleasant experience which is primariff associated with tissue damage or described in terng of tissue damage or both'. These authors hage pointed out that the words of various languages with connotations of pain usually include ideas of mental distress as well as physical pain. In addition other psychological attributes are often involve especially sorrow, punishment, bereavement loss.

\section{Some fallacies}

There are a number of fallacies with regard the clinical aspects of pain. Complaints of pain do

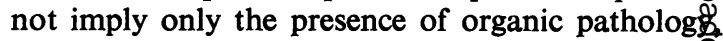
and while physical investigations are usually $\mathbb{\&}$ necessary part of the management of a patient wit pain, negative findings should not be considered an indication that further clinical involvement is unnecessary. It will then be likely that a more psychological approach is required. Severe an persistent pain can be entirely of emotional origi and can respond completely to psychiatric treas ment, as will be described. Physical and psych logical causes of pain are not mutually exclusioe and in most cases both will be relevant, with each aspect requiring assessment.

While it is possible to measure parameters which reflect reactions to pain, the degree of pain expert enced by an individual is impossible to quantify objectively, a problem which has been considered by Beecher (1968). Concerning responses to pain it is hazardous to assume that florid and dramatio complaints or associated behaviour necessari indicate a psychological aetiology. Experiences of pain are difficult to describe and it is not surprising that unusual and idiosyncratic attempts may be made by a patient to communicate what he feelన The description will depend upon the patient? 
verbal facility, the communication between patient and doctor and the patient's personality traits, quite apart from the quality of pain being experienced. Therefore, essentially, the patient's description and attitude are likely to offer as much information about his personality as about his pain. Similarly, with the exception of some cases of migraine, some neuralgias and a few abnormalities of particular cranial nerves, the site of headache is an unreliable indication of its cause.

An attempt is sometimes made to differentiate what is considered to be physical pain from that of emotional origin by the use of a placebo. This misleading method of assessment is not supported by experimental evidence. Even severe pain from physical causes can often be ameliorated, if not always eliminated, by the use of placebo because of effects on the emotional state with consequent modification of the appreciation of the pain. Beecher (1959) has shown that much of the analgesic activity of morphine results from its action in allaying anxiety. Therefore, placebo responses also tend to reveal more about the emotional state of the patient and about his personality than about the type of pain experienced.

\section{Relationship between psychological and organic causes}

There is often an assumption that 'true' pain implies the presence of a physical abnormality while psychogenic pain is not real pain. This was expressed by Butler $\&$ Thomas (1947) who stated that 'psychic headaches are not really headaches', although it is doubtful what this actually means. Other authors, such as Rothenburg (1959) have suggested that in some cases underlying 'real' pain is present but the patient's experience of it is exaggerated by neurosis. Insistence on the presence of organic pathology as an invariable cause of pain is unnecessary but it is probably reasonable to consider as essentially separate, two aspects of pain, as postulated by Hardy, Wolfe \& Goodell (1952) who distinguished pain as a sensation from reactions to it, which may vary independently. Beecher (1959) also described pain as having both a primary sensory component and a processing or reaction component. He maintained that the two cannot be separated completely and their interaction will vary according to circumstances.

A concept of a continuously variable relationship between somatic and psychic aspects is probably realistic and is likely to be clinically useful. It avoids attempting a misleading, rigid dichotomy between physical and psychological factors. No matter how definite the physical damage may be that is causing pain, it will occur in some type of psychological climate which will influence the experience. Attitudes to pain, as a separate dimension from the degree of pain itself, is emphasized in the contrast between the indifference to quite severe injury which can be observed in someone preoccupied by a fight, compared to the agony caused by trivial dental surgery in a person with a neurotic fear of this situation. Similarly, the pain of diseases which are especially feared, such as carcinoma (even if the diagnosis is falsely suspected by the patient) may be more intolerable than severe pain resulting from socially approved injuries such as, for example, those occurring during sports or even in war when there may be heroic and other socially uplifting feelings involved (Beecher, 1956). It can happen that the psychological reaction to pain becomes so prominent as to divert clinical attention completely away from the causal condition.

\section{General aetiological factors}

In his definitive work on headache, which was remarkably little concerned with psychogenic origins, Wolff (1963) suggested that headache arises from three main sources: distension of vessels, spasm of the muscles of the head and neck, and interference, usually traction or distortion, of intracerebral vessels. Migraine is an example of vasodilatation headache while anxiety and tension is said to often produce headache by causing muscular spasm, and vascular effects may also be produced. The third category is exemplified by hypertensive encephalopathy. A committee dealing with the classification of headache (Friedman et al., 1962) accepted fifteen categories of which five could be associated with psychogenic causes: (1) vascular headache of migraine type, (2) muscle-contraction headache, (3) combined headache of first two types, (4) headache of vasomotor discomfort and (5) headache of delusional, conversion and hypochondriacal states. In more general terms, Walters (1961) postulated that there are three ways whereby psychological factors can evoke pain: by psychogenic magnification of physical pain, by emotional stress creating muscle tension and producing muscular pain, and more specific regional pain produced by hysterical mechanisms or by anxiety. Lance (1969) gave a classification which included psychogenic headache only as being either 'depressive, delusional, conversion or hypochondriacal'. These suppositions show little psychiatric sophistication and in most cases with prominent psychological features it will probably be impossible to characterize the headache clearly in one of these ways. Stengel (1965) has pointed out that a mainly physiological orientation is of little help in dealing with psychogenic pain.

In the simplest type of case, the headache is presented as a passport to the doctor in order to obtain his advice about other personal matters. The patient may begin with his complaint of 
headache and then pass to a discussion of his worries which he is unable to present directly. Sometimes in this situation the patient needs help in the transition from the complaint of headache to confiding his problems which he finds are proving a headache for him. If this process is not facilitated by allowing time and understanding, the patient may keep returning with persistent complaints which set up frictions between patient and doctor so that communication is reduced, antagonisms increase and the complaints become chronic.

The social context of the patient is often relevant. In general terms, headache will be more likely to occur in, and to be less easily tolerated by, the lonely, anxious and depressed. Cultural differences can be considerable and, for example, in some societies pains tend to be described floridly and are accompanied by behaviour indicating distress. In contrast, patients of Anglo-Saxon background are more likely to be over-controlled in their complaints of pain and they may be highly suspicious of implications of psychological associations. So much is this so that the present paper is an attempt to show some of their medical attendants that emotional aspects do exist and can often reasonably be expected! These social differences can produce problems in the subjective assessment of complaints of patients with whose cultural background the doctor is unfamiliar.

The family background is also important. For example, illness in some families, and pain in particular, tends to be regarded as of special emotional significance. The source of this may be an emotionally manipulative parent. It may be that whenever the mother, say, has a headache her relatives are expected to pay her a great deal of attention with the result that her child may learn to adopt the same approach. The child may have a familial tendency to headache of some kind but will come to use the symptom in an emotional way and always feel that insufficient attention is given to it by others. Converse factors can also operate. Rejected children who experience pain and distress in which their parents take little interest may subsequently tend to complain excessively in an attempt to gain attention and for fear of being unnoticed. In some cases this process may become a kind of way of life in which complaints of pain and demands for relief are a substitute for seeking the attention and security the patient needs.

Szasz (1968) has presented this idea in what he calls the 'painful person' or homo dolorosus, who, he suggests, depends upon a social milieu which is pervaded by medical values and dominated by the physician. He regards such individuals as 'pursuing a career of pain' which interlocks with the physician whose career is the diagnosis and the relief of such complaints so that 'doctor and patient form couple united by a common enterprise'. He quotes Minogue's (1963) ingenious suggestion that 'the persuader is not a man who must find solutions for problems but one who must construct the problems to fit pre-existing solutions'. Some situations of strife between doctor and patient over complaint of headache probably fit into such an interaction Engel (1959) has also considered in detail the pairg prone patient, in this case in a way which depends largely upon psychoanalytic interpretations.

\section{Headache with psychiatric illnesses}

Headache may be an important symptom in most forms of psychiatric illness, and in many cases will be the presenting complaint. However, pain less likely to be encountered in cases of schizod phrenia. Certainly schizophrenic patients sometimes present hypochrondriacal complaints of malfung tion, including head symptoms, and these mags often be given a delusional interpretation. But there is a good deal of evidence that schizophrenia $\mathrm{R}$ usually associated with considerably impaired reactions to painful stimuli (Bellak \& Loeb, 1969).

Endogenous depression is, by contrast, an illnes

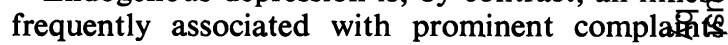
of pain, most often involving the head but also face, abdomen and elsewhere. Headache was fornd to have occurred as one of the chief complaints among $71 \%$ of Campbell's (1953) series of depreșed patients and even more of the patients reporte headache or a pressure feeling in the head on previous occasion during their illness. He suggeste that the headache was of vasomotor origin as the patients could feel a pulse beating in their head and the symptoms were often made worse during attacks of tachycardia. In a comparative stud Cassidy, Flanagan \& Spellman (1957) found that headaches were reported by $49 \%$ of depresse patients, $36 \%$ of medically sick controls and as many as $25 \%$ of healthy controls. Bridges, Kolle \& Wheeler (1966) reported on a group of patients in a general hospital who were referred for psych 5 atric assessment because no organic cause had beef found for their physical complaints, most of which were of pain, and it was considered that two-thirds were suffering from endogenous depression. Bradle (1963) studied thirty-five patients with depressiow and pain without demonstrable organic causa He was able to distinguish two groups, in one of which chronic pain was followed by depression ang the depression alone responded to treatment but there was also increased tolerance of the pain after recovery. In the other group both the pain an 8 depression were relieved simultaneously by treat: ment of the depression. Headache and other pain may sometimes be appropriately considered 
'depressive equivalents' when patients complain of somatic complaints without depression of mood, although other depressive symptoms may be elicited on careful enquiry, such as loss of energy, anorexia and sleep disturbance.

Tension and anxiety are likely to be important ingredients of all forms of neurosis, including phobic states, neurotic depression and obsessional neurosis, as well as in anxiety neuroses. Thus, headache can be a prominent symptom in all such cases and factors relevant to the aetiology of headache in such patients would include muscle tension and reduced pain tolerance. In addition, as in the case of depression, pain may sometimes be a symptom equivalent for anxiety and for other emotional conflicts (Pilling, Brannick \& Swenson, 1967). The explanation of muscle tension as the intermediate factor between anxiety and headache is not always appropriate. It is not uncommon to find that when a close relative has died of, say a cerebral tumour, part of the resulting expression of distress in the patient echoes the relative's illness and headache is complained of. Another frequently encountered symbolic symptom is chest pain following the death of a relative from heart disease.

Hysteria is a form of neurosis which is often difficult to assess. Hysterical headache is not merely headache in which no organic cause can be found and it should not be diagnosed only on the basis of complaints of headache which are apparently exaggerated. A positive diagnosis of hysteria may be complex and will depend upon a psychiatric assessment from which is revealed relevant psychogenesis and evidence of conversion involving the translation of emotional problems to a physical complaint or defect. This is an unconscious neurotic mechanism which is more complex than simply a means of manipulating others, although this aspect may be important. In this respect the hysterical personality trait, which includes histrionic, manipulative and demanding behaviour, should be differentiated from a hysterical conversion symptom. The former is a personality type and the latter a specific neurotic illness.

The concept of psychosomatic diseases as a relatively well-defined group is probably now being viewed less favourably. All illnesses are psychosomatic in the sense that there are likely to be both psychological and physical aspects to the aetiology. Usually one or other predominates but in a number of illnesses the contributions from mind and body are of relatively similar emphasis. This tends to increase problems of evaluation and treatment, both of which may have to be wider in scope than with illnesses which are more clearly either largely physical or psychological. From the point of view of headaches, migraine comes within this category and it has been reviewed from the psychosomatic standpoint by Elithorn (1969). He stresses the diffities in assessing the many treatments for this condition and shows that an eclectic therapeutic approach is essential, which has to be suited to the clinical presentation of each individual patient, evaluated from all aspects, both physical and emotional.

\section{Treatment}

Therapy must depend upon adequate assessment. Physical examination will be necessary and investıgations will be carried out as indicated. A full psychiatric history is also required, together with an opportunity for the patient to talk freely about himself. In this way problems may be communicated which are concealed during more formal history taking. Simple reassurance is essentially a negative approach which is therapeutically of limited value. It is likely to be insufficient to tell the patient only that a headache is of no physical significance or that there is no organic disease present. This particular aspect may be only a small part of the patient's anxieties or it may not be relevant at all when the patient is preoccupied by a major emotional disturbance or by a distressing headache rather than by a fear of physical disease.

When there is a physical abnormality present this should be discussed with the patient, even in cases with a poor prognosis. When the outlook is grave more definite information, even although it implies a serious illness, can help the patient to adjust and secondary psychological tension may be reduced when he understands better the problem with which he has to cope. It will also be of value to patients to understand that emotional factors can reasonably play a part in their reaction to an unpleasant organic headache.

Occasionally rapid relief of psychogenic headache can be obtained after locating an emotional conflict which is then resolved by discussion, and an attempt at this approach is always a useful aim, timeconsuming though it usually is. In other cases the patient can be shown that his reactions to particular life stresses include headache, and an understanding of his vulnerability may help him to come to terms more effectively both with problems as they arise and with the symptom. As Friedman (1951) has pointed out, it is well to take into account that many patients will feel that the idea of treating what they regard as 'real pain' by just talking about it is ridiculous and the physician will need to deal with such aspects as the reality of psychogenic pain and the validity of pain resulting from emotional causes.

Psychiatric conditions may be encountered when assessing patients with headache which are likely to be difficult to deal with and in some cases the 
presence of emotional difficulties is in doubt. In these circumstances psychiatric referral should be considered. A book concerned with the treatment of headache suggests that if there is evidence of serious psychiatric disease the patient should be referred for a specialist opinion. This is, of course, true but severity is not the only criterion. Patients in whom there is a diagnostic problem and those with chronic complaints, even when not severe, may need specialized evaluation. When significant depression is revealed the need for expert assessment is often required because of the possibility of deterioration with increasing suicidal risk. Formal psychotherapy, as opposed to more casual therapeutic discussions, can be effectively employed by family doctors who have an understanding of this type of treatment and who have the time available, but it can prove to be an exacting and lengthy procedure which should not be undertaken lightly.

Another book on headache states that the specific treatment of psychogenic headache is psychotherapy. This is certainly inaccurate for medication can play an important or paramount therapeutic role in many cases. Drugs for the more organic types of headache are not considered here. Analgesics are to be avoided in cases of psychogenic headache and also in those patients with organic headache in which there is a significant emotional contribution, for such drugs deal only with effects rather than causes; their use can easily become chronic and dependence is likely. The frequency with which analgesics are abused by patients with psychogenic headache and the resulting medical complications caused, have been described by Murray, Timbury \& Linton (1970).

Sedative types of medication are of value in the presence of tension or anxiety. Barbiturates, although highly effective in this action, should not be used because of the dangers of dependence and overdose. The phenothiazines (e.g. chlorpromazine (Largactil), trifluoperazine (Stelazine) etc.) are of limited value in these cases for, contrary to a common clinical belief, they have only weak anxiety-reducing activity (Shepherd, Lader \& Rodnight, 1968). But chlorpromazine (Largactil) and promazine (Sparine) are said to have analgesic properties and may therefore be useful for a few patients (Modell, 1970). Meprobamate (Equanil, Miltown) has muscle relaxant properties as well as an anxiolytic action and so may be of value in cases with prominent muscle tension. However, the best drugs to use are the benzodiazepines which include chlordiazepoxide (Librium), diazepam (Valium), oxazepam (Serenid) and medazepam (Nobrium). These compounds reduce anxiety and tension without normally causing drowsiness, they are relatively safe even when taken in overdose and true dependence seems very rare.

A practical study of the treatment of chronic $\stackrel{\mathbb{Q}}{\mathbb{Q}}$ headache was carried out by Lance \& Curran (1964) $\subseteq$. who observed the effects of twelve treatments on $\vec{F}$ 280 patients selected from those attending a head- $\stackrel{\sim}{+}$ ache clinic. The treatments included amylobarbitone (Amytal), various vasodilators, Bellergal, methyser- $\frac{\bar{D}}{\bar{D}}$ gide, chlordiazepoxide (Librium) and several anti- $\frac{\sigma}{\overrightarrow{0}}$ depressants as well as placebo. The best results were $\stackrel{\square}{\square}$ obtained from the anti-depressant amitriptyline $\stackrel{\oplus}{\infty}$ (Tryptizol) on which over $50 \%$ of patients were free $\vec{\circ}$ of headache or much improved and this occurred in some cases where the symptom had been present $\bar{\omega}$ for very long periods. Other effective drugs were Bellergal, chlordiazepoxide (Librium), diazepamo (Valium) and imipramine (Tofranil) while the drugs with effects not significantly different from placebo $\stackrel{-}{-}$ were amylobarbitone (Amytal), the vasodilators of (Ronicol, ergot alkaloids, nicotinic acid), methysergide, orphenedrine (Disipal) and Parstelin. The of selection of patients, which appeared to exclude those with more specific forms of headache such as migraine, no doubt accounts for some of these findings but the responses observed suggest the considerable importance of psychological factots $\frac{1}{\infty}$ among patients with headache, of which depression appears to be the most important. The finding 9 indicate that anti-depressant medication should tried in many cases of headache and especially those who show some other symptoms of depression. These symptoms include early morning waking, $\bar{\partial}$ loss of energy, of interest and of concentration, anorexia, sleep disturbance and depressed mood. $\stackrel{\mathbb{D}}{\square}$ Diagnostic uncertainty may arise when the patient $\overrightarrow{\vec{O}}$ attributes depression and insomia to the headache when the reverse may be true.

Normally, only the tricyclic group of antidepressants should be used as these are much safer $\vec{\partial}$ drugs than the monoamine oxidase inhibitors. Tricyclic preparations include, among many others, $\dot{\sigma}$ imipramine (Tofranil) and amitriptyline (Tryptizol). It is important, because of the prevalence of side- $\delta$ effects, that the dose is not large to begin with and perhaps $25 \mathrm{mg}$ b.d. or t.d.s. of one of the drugs 을 mentioned could be used, increasing to perhaps $\rightarrow$ $50 \mathrm{mg}$ t.d.s. Little or no response can be expected before 2 weeks on this dose, which needs to be $\bar{N}$ maintained for at least 4 weeks before the effect ? can be adequately assessed. Therapeutic failure is $\mathbb{O}$ often incorrectly assumed after the use of too small $N_{\omega}^{N}$ a dose for too short a time. Patients with depression usually need careful assessment and regular observa- 0 tion because of the possibility of deterioration and $\frac{\bar{D}}{\Phi}$ of a suicidal risk. In some cases electroconvulsive $\stackrel{?}{+}$ therapy may need to be considered. For suitable 0 patients with chronic incapacitating depression or 
anxiety psychosurgery may be of value (StrömOlsen \& Carlisle, 1971).

\section{Acknowledgments}

I am grateful to Mr. Geoffrey Knight for valuable advice and to Mrs B. Groves for secretarial help.

\section{References}

BEECHER, H.K. (1956) Relationship of significance of wound to the pain experienced. Journal of the American Medical Association, 161, 1609.

BEECHER, H.K. (1959) Measurement of Subjective responses. Quantitative effects of drugs. Oxford University Press, New York.

BEECHER, H.K. (1968) The measurement of pain in man. In: Pain (Ed. by A. Soulairac, J. Cahn \& J. Charpentier). Academic Press, London.

BellaCK, L. \& Loeb, L. (1969) The Schizophrenic Syndrome. Grune \& Stratton, New York.

BRADLEY, J.J. (1963) Severe localized pain associated with the depressive syndrome. British Journal of Psychiatry, $109,741$.

Bridges, P.K., Koller, K.M. \& Wheeler, T.K. (1966) Psychiatric referrals in a general hospital. Acta psychiatrica Scandinavica, 42, 171.

Butler, S. \& Thomas, W.A. (1947) Headache: its physiologic causes. Journal of the American Medical Association, $135,967$.

Campbell, J.D. (1953) Manic-Depressive Disease. J.B. Lippincott Co., London.

Cassidy, W.L., Flanagan, N.B. \& Spellman, M. (1957) Clinical observations in manic-depressive disease. Journal of the American Medical Association, 164, 1535.

ElithoRn, A. (1969) Migraine. British Medical Journal, 4, 411.

Engel, G.L. (1959) Psychogenic pain and the pain-prone patient. American Journal of Medicine, 26, 899.
Friedman, A.P. (1951) Modern Headache Therapy. C.V. Mosby Co., St Louis.

Friedman, A.P., Finley, K.H., Graham, J.R., Kunkle C.E., OSTFEld, M.O. \& WolfF, H.G. (1962) Classification of headache. Archives of neurology, 6, 173.

Hardy, J.D., Wolfe, H.G. \& Goodell, H. (1952) Pain Sensations and Reactions. Williams \& Wilkins, Baltimore.

LANCE, J.W. (1969) The Mechanism and Management of Headache. Butterworths, London.

LANCE, J.W. \& Curran, D.A. (1964) Treatment of chronic tension headache. Lancet, i, 1236.

Lewis, T. (1942) Pain. Macmillan Co., New York.

Mersky, H. \& Spear, F.G. (1967) Pain, Psychological and Psychiatric Aspects. Baillière, Tindall \& Cassell, London.

Minogue, K.R. (1963) The Liberal Mind. Methuen, London.

Modell, W. (1970) Drugs of Choice 1970-71. C.V. Mosby Co., St Louis.

Murray, R.M., Timbury, G.C. \& Linton, A.L. (1970) Analgesic abuse in psychiatric patients. Lancet, i, 1303.

Pilling, L.F., Brannick, T.L. \& Swenson, W.M. (1967) Psychologic characteristics of psychiatric pain having pain as a presenting symptom. Canadian Medical Association Journal, 97, 387.

RothenbURG, S.F. (1959) Postoperative intractable pain. Medical Clinics of North America, 43, 1243.

ShePherd, M., LAder, M. \& Rodnight, R. (1968) Clinical Psychopharmacology. English Universities Press, London.

Stengel, E. (1965) Pain and the psychiatrist. British Journal of Psychiatry, 111, 795.

Ström-Olsen, R. \& Carlisle, S. (1971) Bi-frontal stereotactic tractotomy. British Journal of Psychiatry, 118, 141.

Szasz, T.S. (1957) Pain and Pleasure. Basic Books, New York.

SzASZ, T.S. (1968) The psychology of persistent pain. In: Pain (Ed. by A. Soulairac, J. Cahn \& J. Charpentier). Academic Press, London.

Walters, A. (1961) Psychogenic regional pain alias hysterical pain. Brain, 84, 1.

Wolff, H.G. (1963) Headache and Other Headpain. Oxford University Press, New York. 